\title{
The Road to Recovery for Patients with Depression: From Treatment Initiation to Treatment Continuity
}

Ronnachai Kongsakon

Received: September 15, 2021 / Accepted: December 17, 2021 / Published online: March 5, 2022

(C) The Author(s) 2022

Keywords: Depression; Patient-physician relationship; Shared-decision making

\section{Key Summary Points}

Depression is highly prevalent worldwide and is associated with a significant economic burden on society.

In the past, patients with major depressive disorder have experienced a 'paternalistic' interaction with their physician, contributing to poor treatment outcomes.

This supplement highlights the importance of a shared decision-making approach to treatment, from treatment initiation through to remission and restoration of functioning.

\section{EDITORIAL}

Depression is a prevalent mental disorder, affecting 322 million people worldwide [1]. In Thailand, the home country of this author, depression affects $4.4 \%$ of the population [1].

R. Kongsakon $(\bowtie)$

Faculty of Medicine, Ramathibodi Hospital, Mahidol University, 270 Praram 6 Rd, Rajthevi, Bangkok 10400, Thailand

e-mail: ronnachaikong@gmail.com;

rarks@mahidol.ac.th
The World Health Organization (WHO) found that over $4 \%$ of the population worldwide had an episode of depression in 2015 [1]. It is perhaps unsurprising, then, that depression is described by the WHO as the largest single contributor to disability globally [1]. The disability associated with depression may be viewed at an individual level, and includes, for example, a patient's reduced ability to interact with their friends, family and colleagues [2, 3] or at a societal level, where it leads to significant workplace productivity losses [3, 4]. Depression is associated with high levels of morbidity and mortality (in 2019, there were approximately 2000 deaths by suicide every day worldwide) [5], and ultimately places a severe economic burden on society [6].

There is significant room for improvement in the way patients with depression are managed and treated; currently, only $22.4 \%$ of patients with depression from high-income countries are considered to receive adequate treatment, and this figure is dramatically lower for patients from low- or lower-middle-income countries (where $3.7 \%$ of patients are adequately treated) [7].

While clinicians are very familiar with the range of therapeutic options (from pharmacotherapy through to social and lifestyle interventions) and the range of medications available (antidepressants, antipsychotics, mood stabilisers, etc.) to treat a patient with major 
depressive disorder, they may be less familiar with the shared decision-making approach to treatment, as evidenced by the following statistics:

- Fewer than $50 \%$ of patients believe they receive clear information about treatment options [8].

- Fewer than $10 \%$ of treatment decisions meet the minimum standards for informed decisionmaking [9].

Why should clinicians engage in shared decision-making with patients? Evidence suggests this approach improves remission rates (Fig. 1a, b) [10, 11], which would help address the significant gaps in the management of depression. Patient involvement means deciding upon a management/treatment strategy that is most consistent with the patient's values and preferences [12], as discussed in detail in Siegfried Kasper's article entitled 'Initiating antidepressant medication: what is the most important factor?'.

When patients are asked what their top priorities for antidepressant treatment are, "Presence of positive mental health (e.g. optimism, vigour, self-confidence)", "Feeling like your usual, normal self", and "Return to usual level of functioning at work, home or school" rank as the top 3 [13]. Establishing a bi-directional

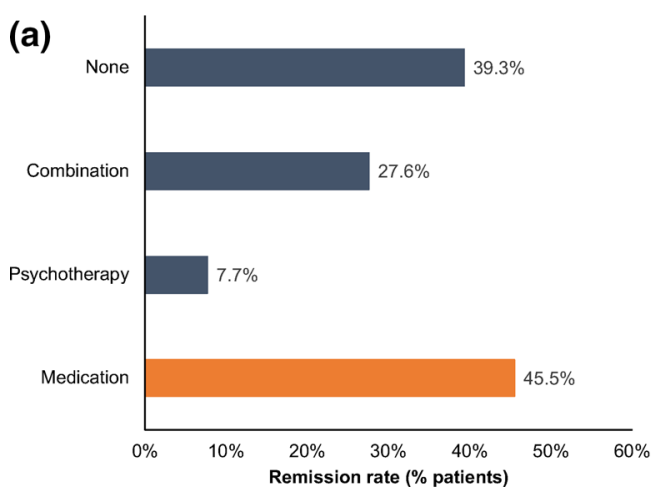

Fig. 1 Remission rates by treatment preference (shown on the $y$ axes) among a patients treated with medication and b patients treated with psychotherapy, in a study population of adults with major depressive disorder $(n=429)$ [10]. Republished with permission of Physicians Postgraduate Press, from Kocsis et al. Patient preference as a therapeutic partnership from the very beginning helps address patients' beliefs and expectations about antidepressant treatment.

Recognising the need to shift the patient-clinician relationship from a paternalistic unidirectional relationship to a shared, bidirectional approach fits within the conceptual framework outlined by Dan Stein, in his article entitled 'Engaging patients with depression in treatment continuity'. Here, Professor Stein explains how physicians treating patients with major depressive disorder need to understand the 'illness', defined as the physical, social and cultural construct in which the disease is experienced, as well as the 'disease' - the pathophysiological entity-and that this understanding underpins shared decisionmaking.

An important aspect of the treatment of depression, but one that historically has been overlooked, is improving functional outcomes, as highlighted by Sidney Kennedy's article in this supplement 'Beyond response: aiming for quality remission in depression'. In this article, Professor Kennedy further explores the concept that antidepressant treatment should improve functional outcomes, which are an indicator of meaningful change (i.e. quality remission without residual symptoms), and how this might be achieved. Examples of therapeutic

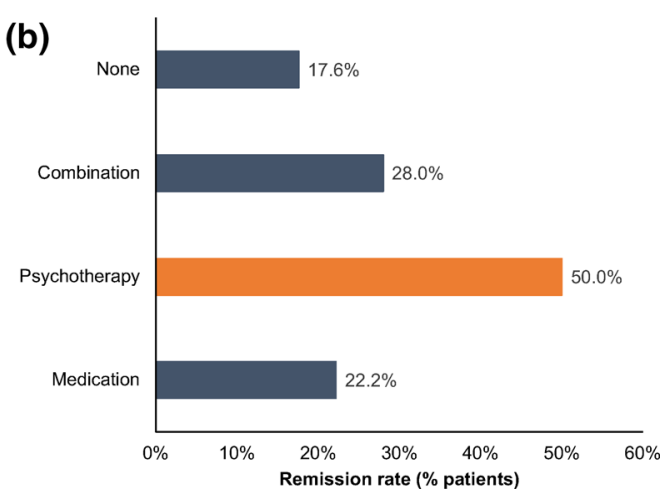

moderator of outcome for chronic forms of major depressive disorder treated with nefadozone: cognitive behaviour analysis system of psychotherapy, or their combination. J Clin Psychiatry 2009 70(3): 354-361; permission conveyed through Copyright Clearance Center, Inc 
strategies include treatment with combination therapy or with a single agent that has been shown to improve symptomatic and functional response (e.g. agomelatine).

In conclusion, a key goal of patient management is engendering the shared sense of "We're in this together". This begins with employing shared decision-making, from the selection and initiation of treatment through to working towards common goals, ultimately aiming for treatment remission and the restoration of patient functioning.

\section{ACKNOWLEDGEMENTS}

Funding. This editorial is based on a presentation given by Prof. Kongsakon at a satellite symposium entitled Road to Recovery for Depressed Patients: From Treatment Initiation to Continuity. The symposium formed part of the programme of the WPA World Congress of Psychiatry, held 10-13 March 2021. The satellite symposium was sponsored by Servier, which also provided funding for the journal's Rapid Service and Open Access Fees. The supplement was sponsored by Servier.

Medical Writing. The author would like to thank Tracy Harrison of Springer Healthcare Communications, who wrote the first draft of the manuscript based on the corresponding presentation at WPA World Congress of Psychiatry 2021. Funding for the writing was provided by Servier.

Authorship. The named author of this article meets the International Committee of Medical Journal Editors (ICMJE) criteria for authorship for this article, takes responsibility for the integrity of the work as a whole, and has given his approval for this version to be published.

Author Contributions. Prof. Kongsakon prepared the content of the presentation on which this article was based and reviewed and revised all drafts of the manuscript.
Prior Presentation. This editorial is based on a presentation given by the author at a satellite symposium entitled Road to Recovery for Depressed Patients: From Treatment Initiation to Continuity. The symposium formed part of the programme of the WPA World Congress of Psychiatry, held virtually from 10 to 13 March 2021. The content of the presentation and this article are based on work that has been previously published.

Disclosures. Prof. Kongsakon has nothing to disclose. Servier has participated in the development of this editorial.

Compliance with Ethics Guidelines. This article is based on previously conducted studies and does not contain any new studies with human participants or animals performed by any of the authors.

Open Access. This article is licensed under a Creative Commons Attribution-NonCommercial 4.0 International License, which permits any non-commercial use, sharing, adaptation, distribution and reproduction in any medium or format, as long as you give appropriate credit to the original author(s) and the source, provide a link to the Creative Commons licence, and indicate if changes were made. The images or other third party material in this article are included in the article's Creative Commons licence, unless indicated otherwise in a credit line to the material. If material is not included in the article's Creative Commons licence and your intended use is not permitted by statutory regulation or exceeds the permitted use, you will need to obtain permission directly from the copyright holder. To view a copy of this licence, visit http://creativecommons.org/licenses/by$\mathrm{nc} / 4.0 /$.

\section{REFERENCES}

1. World Health Organization. Depression and Other Common Mental Disorders: Global Health Estimates. Geneva; 2017. Contract No.: 18 May. 
2. Association AP. Diagnostic and Statistical Manual of Mental Disorders (DSM-5). American Psychiatric Association; 2013.

3. World Federation for Mental Health. Depression: A global crisis. World Mental Health Day. 2012. https://www.who.int/mental_health/management/ depression/wfmh_paper_depression_wmhd_2012. pdf. Accessed Oct 10, 2012.

4. Krol M, Papenburg J, Koopmanschap M, Brouwer W. Do productivity costs matter?: the impact of including productivity costs on the incremental costs of interventions targeted at depressive disorders. Pharmacoeconomics. 2011;29(7):601-19.

5. World Health Organization. Suicide worldwide in 2019: global health estimates. Geneva: World Health Organization; 2021. Report No.: ISBN: 9789240026643.

6. World Health Organization. Mental health atlas 2017. Geneva; 2018. Report No.: ISBN: 978-92-4151401-9.

7. Thornicroft G, Chatterji S, Evans-Lacko S, Gruber $\mathrm{M}$, Sampson N, Aguilar-Gaxiola $\mathrm{S}$, et al. Undertreatment of people with major depressive disorder in 21 countries. $\mathrm{Br} \mathrm{J}$ Psychiatry. 2017;210(2):119-24.

8. Smith M, Saunders R, Stuckhardt L, et al. Summary, the path (engaging families and communities). In: Committee on the Learning Health Care System in America, Institute of Medicine. Best Care at Lower Cost: The Path to Continuously Learning Health Care in America. Washington DC: National Academies Press; 2013; S159.
9. Oshima Lee E, Emanuel EJ. Shared decision making to improve care and reduce costs. N Engl J Med. 2013;368(1):6-8.

10. Kocsis JH, Leon AC, Markowitz JC, Manber R, Arnow B, Klein DN, et al. Patient preference as a moderator of outcome for chronic forms of major depressive disorder treated with nefazodone, cognitive behavioral analysis system of psychotherapy, or their combination. J Clin Psychiatry. 2009;70(3): 354-61.

11. Hopwood M. The shared decision-making process in the pharmacological management of depression. Patient Patient Centered Outcomes Res. 2020;13(1): 23-30.

12. Barry MJ, Edgman-Levitan S. Shared decision making-pinnacle of patient-centered care. $\mathrm{N}$ Engl J Med. 2012;366(9):780-1.

13. Zimmerman M, McGlinchey JB, Posternak MA, Friedman M, Attiullah N, Boerescu D. How should remission from depression be defined? The depressed patient's perspective. Am J Psychiatry. 2006;163(1):148-50. 